\title{
Determining Information on Cardiology Disease Risk Factors of Disease in Women
}

\author{
Hasret Yalçınöz Baysal, ${ }^{1}$ Sonay Bilgin,, ${ }^{1}$ Işın Cantekin, ${ }^{2}$ and Gökhan Bilgin ${ }^{3}$ \\ ${ }^{1}$ Department of Medical Nursing, Health Sciences Faculty, Ataturk University, Erzurum, Turkey \\ ${ }^{2}$ Department of Internal Medical Nursing, Faculty of Health Sciences, Meliksah University, Mevlana Mahallesi, \\ Aksu Sokak, 38280 Talas, Kayseri, Turkey \\ ${ }^{3}$ Public Health Agency, Erzurum, Turkey
}

Correspondence should be addressed to Işın Cantekin; icantekin@meliksah.edu.tr

Received 14 March 2014; Revised 22 April 2014; Accepted 30 April 2014; Published 3 July 2014

Academic Editor: Giuseppe Biondi-Zoccai

Copyright (C) 2014 Hasret Yalçı̈öz Baysal et al. This is an open access article distributed under the Creative Commons Attribution License, which permits unrestricted use, distribution, and reproduction in any medium, provided the original work is properly cited.

\begin{abstract}
In an attempt to decrease the rate of mortality from cardiovascular diseases, first cardiovascular risk factors should be controlled. This study was carried out to reveal the level of knowledge about cardiovascular disease risk factors in women who presented to a primary healthcare center in Erzurum, Turkey, and the prevalence of such risk factors. Our study is a descriptive one and its data were collected between February and April 2013. The study included 168 women who presented to Filiz Dolunay Family Healthcare Center and who met the criteria and agreed to participate in the study. It was found that $22.6 \%$ of the women did not exercise at all above normal range, $53.6 \%$ of them had weights above normal, $23.8 \%$ smoked, and $22 \%$ had hypertension, type 2 diabetes, cholesterol, or excess fat around their waist. It was concluded that, although women were knowledgeable, they did not put this into practice in their lives.
\end{abstract}

\section{Introduction}

Cardiovascular diseases (CVD) play an increasingly important role as the major cause of mortality and morbidity and are one of the leading health issues across the world [1-3].

In our country, deaths associated with cardiovascular diseases (CVD) are at the top of the list. In an attempt to decrease the rate of mortality from cardiovascular diseases, cardiovascular risk factors should be brought under control. Economic transformation, urbanization, industrialization, and globalization inducing life style changes such as tobacco use, physical inactivity, and unhealthy diet are strictly correlated with the progression of heart diseases. Life expectancy rises rapidly in developed and developing countries and people are exposed to these risk factors for a longer time [4].

Increased rates of obesity, metabolic syndrome, and smoking in women today lead to a significant rise in morbidity and mortality associated with cardiovascular diseases. Turkish women in particular demonstrate much more negative characteristics than men in terms of some risk factors [5].
Among the cardiovascular risk factors, age, gender, and genetic/ethnical factors are in the "unchangeable factors" group. Cigarettes and other tobacco products, unhealthy eating habits, sedentary living, being overweight, dyslipidemia, hypertension, and diabetes are in the main "modifiable" cardiovascular risk factors group [1].

Individuals can lower their cardiovascular disease risk by engaging in regular physical activity, avoiding tobacco use and passive smoking, choosing a fruit and vegetable rich diet, avoiding food rich in fats, salt, and sugar, and maintaining a healthy body weight [1]. Health professionals should find out to what extent women are knowledgeable about the risk factors and risk reducing behaviors in CVD.

This study was carried out to reveal the level of knowledge about cardiovascular disease risk factors in women who presented to a primary healthcare center in Erzurum, Turkey, and the prevalence of such risk factors.

\section{Methods}

2.1. Study Design. Our study is a descriptive one and its data were collected between February and April 2013. The study 
included 168 women who presented to Filiz Dolunay Family Healthcare Center and who met the criteria and agreed to participate in the study. The questionnaires were completed by the investigator in 20 minutes by way of face-to-face interviews.

Criteria are as follows:

(i) nonhearing problems,

(ii) nonpsychological discomfort,

(iii) 18 women over the age.

\subsection{Data Collection Tool}

2.2.1. The Cardiovascular Disease Risk Factors Knowledge Level (CARRF-KL) Scale. The Cardiovascular Disease Risk Factors Knowledge Level (CARRF-KL) Scale, which was prepared by Wagner et al., was tested for validity and reliability in Turkey by Arikan et al. $[6,7]$. The first four items in the scale relate to the characteristics of CVD, avoidance of them, and age factor, 15 items question risk factors (items 5, 6, 9-12, 14, 18-20, 2325,27 , and 28), and nine items (items $7,8,13,15,16,17,21,22$, and 26) question the resulting change in risk behavior. The items in the scale are presented as complete sentences which can be true or false and the participants are asked to answer these expressions as "yes," "no," or "do not know." Each true response is given 1 point. The expressions in six of the sentences in the scale are false. These items are coded in reverse order as compared to the others. The highest total score that can be obtained from the scale is 28. Cronbach's alpha value of the scale is 0.768 . Cronbach's alpha value of our study was 0.786 .

The revised questionnaire was pretested in a pilot study held within the author's workplace and a number of minor adjustments were made to the original version.

2.3. Process. The questionnaires were completed by the investigator in 20 minutes by way of face-to-face interviews. The women who came to Filiz Dolunay Family Healthcare Center for primary healthcare and who met the criteria were provided with information about the study and those who agreed to take part in the study were included in the study. Data were entered into the Statistical Package for Social Sciences 15.0 for Windows (SPSS Inc., Chicago, IL, USA) and checked for accuracy. Questions relating to the Heart Belief Fact Questionnaire-2 were tallied by correct response and totaled. The scores were recorded on a Microsoft Office Excel spread sheet.

2.4. Review Board Approval. Only patients who voluntarily consented to participate were included in the study. Assurance was given that confidential personal information would not be disclosed. Permission to conduct the study was obtained from the Health Sciences Institute Ethics Committee.

\section{Results}

The ages of the women who took part in the study ranged between 30 and 75 . The percentages of the true responses given by women to the questions are shown in Table 1 .

The heart disease risks women have are shown in Table 2. It was found that $22.6 \%$ of the women did not exercise, $53.6 \%$ of them had weights above normal, $23.8 \%$ smoked, and $22 \%$ had hypertension, type 2 diabetes, cholesterol, or excess fat around their waist.

The women were classified with respect to heart disease and knowledge level in Table 3 . There were 24 women with " 0 " risk factor, 32 women with " 1 " risk factor, 44 women with " 2 " risk factors, 40 women with " 3 " risk factors, and 28 women with " 4 " risk factors.

The mean scores obtained by the women from the scale were $18 \pm 26$ in those with " 0 " risk factor, $16 \pm 24$ in those with " 1 " risk factor, $12 \pm 20$ in those with " 2 " risk factors, $10 \pm 18$ in those with " 3 " risk factors, and $10 \pm 16$ in those with " 4 " risk factors, the mean total score being $10 \pm 26$.

\section{Discussion}

Although heart diseases have a significant place among the death rates in female population in our country, very few studies have been performed in relation to this issue. We tried in this study to determine how knowledgeable women were in heart diseases and to what extent they put their knowledge into practice.

The mean score the women obtained from the Cardiovascular Disease Risk Factors Knowledge Level was found to be $10 \pm 26$ in the study. Although the women had moderate levels of knowledge (the total score ranged between 0 and 28), they had one or two risk factors for heart diseases. Other studies that have been conducted on the subject support this study [8-10].

It was found in the Turkish Population and Health Survey (TNSA-2008) that $34.4 \%$ of women in the $15-49$ age group were overweight and $23.9 \%$ of them were obese [11]. It was also stated that the prevalence of obesity ranged between $24.6 \%$ and $61 \%$ in women and it was twice that in men [12-14].

Approximately $60-85 \%$ of adults are not active enough to be healthy [15].

In a study made by the Ministry of Health, the percentage of those who practiced regular physical activity across the country was as low as $3.5 \%$. In other words, $96.5 \%$ of the nation fails to practice regular physical activity [16]. It was found in another study that $20.3 \%$ of all individuals lead a sedentary life and $16 \%$ of them practiced insufficient physical activity [17]. Our study results are in parallel with these studies assessing physical activity habits and show that physical activity has not yet become a life style in our country.

According to the results of another study conducted in our country, $22.8 \%$ of the sample, $51.1 \%$ of which consisted of women, was in the obese category, $36.8 \%$ were overweight, and $34.1 \%$ had a normal body mass index and the percentage of those who did not exercise in the whole sample was $62.8 \%$ [18]. In their study, Gocgeldi et al. found that the patients who 
TABLE 1: Responses to Heart Disease Fact Questionnaire.

\begin{tabular}{|c|c|c|}
\hline \multirow{2}{*}{ Question } & \multicolumn{2}{|c|}{ Correct response } \\
\hline & $(N=168)$ & $n \%$ \\
\hline A person can always realize that he/she has a heart disease. & 110 & 65.4 \\
\hline Having heart disease in your family increases your risk of having a heart disease. & 100 & 59.5 \\
\hline The elderly have a higher risk of heart disease. & 145 & 86.3 \\
\hline Coronary heart disease can be prevented. & 92 & 54.7 \\
\hline The avoidable cause of deaths and diseases in our country is smoking. & 132 & 78.5 \\
\hline Smoking is a risk factor for heart disease. & 146 & 86.9 \\
\hline If one quits smoking, risk of developing a heart disease diminishes. & 144 & 85.7 \\
\hline Eating 2-3 fruits and 2 servings of vegetable dishes a day is beneficial. & 158 & 94 \\
\hline Consuming red meat more than 3 times a week is harmful. & 69 & 41 \\
\hline Salty food provokes hypertension. & 159 & 94.6 \\
\hline Fatty foods do not elevate the cholesterol level in blood. & 151 & 89.8 \\
\hline Fats that are solid in room temperature are good for heart health. & 98 & 58.3 \\
\hline Eating a diet low in fats and carbohydrates is beneficial for the heart. & 109 & 64.8 \\
\hline Overweight people have higher risk of heart disease. & 134 & 79.7 \\
\hline Regular exercise lowers heart disease risk. & 147 & 87.5 \\
\hline Risk is reduced only through exercise in gymnasia. & 104 & 61.9 \\
\hline Slow walk and strolling around can be considered as exercise. & 90 & 53.5 \\
\hline Stress, grief, and sadness increase risk of heart disease. & 107 & 63.9 \\
\hline Human body increases the blood pressure in stressful situations. & 143 & 85.1 \\
\hline Hypertension is a risk factor for heart disease. & 154 & 91.6 \\
\hline Keeping blood pressure under control reduces the risk of developing a heart disease. & 134 & 79.7 \\
\hline Antihypertensive drugs should be used lifelong. & 105 & 62.5 \\
\hline High cholesterol is a risk factor for heart disease. & 132 & 78.5 \\
\hline If good cholesterol (HDL) is high, there is risk of heart disease. & 65 & 38.6 \\
\hline If bad cholesterol (LDL) is high, there is risk of heart disease. & 93 & 55.3 \\
\hline Medication is given to everybody who has high cholesterol. & 78 & 46.4 \\
\hline Diabetes is a risk factor for heart disease. & 87 & 51.7 \\
\hline If sugar is kept under control in diabetic patients, risk decreases. & 96 & 57.1 \\
\hline
\end{tabular}

TABLE 2: Heart disease risk factor.

\begin{tabular}{lcc}
\hline Variable & Number & Percent \\
\hline Hypertension & 37 & 22 \\
Diabetes mellitus type 2 & 37 & 22 \\
Overweight & 90 & 53.6 \\
Dyslipidemia & 37 & 22 \\
Smoking & 40 & 23.8 \\
Lack of exercise & 38 & 22.6 \\
Abdominal adiposity & 37 & 22 \\
\hline
\end{tabular}

were overweight according to their body mass indexes had significantly lower scores from the general health scale [19].

Prevention in the setting of heart diseases requires a proper life style. Rosenberg et al. [20] and Kawachi et al. [21] found in their studies that female patients who smoked had a higher risk of developing heart diseases.

Mahanonda et al. investigated in their studies the effect of regular exercising on cardiovascular risk factors and found that the resting heart rate was quite lower in the group not exercising regularly than in the group exercising regularly
TABLE 3: The mean values of the risk factors of cardiovascular disease.

\begin{tabular}{lccc}
\hline Total risk factors & $N$ & Mean & Minimum-maximum \\
\hline 0 & 24 & 19.3 & $18 \pm 26$ \\
1 & 32 & 21.5 & $16 \pm 24$ \\
2 & 44 & 15.6 & $12 \pm 20$ \\
3 & 40 & 19.1 & $10 \pm 18$ \\
4 & 28 & 17.6 & $10 \pm 16$ \\
\hline Total & 168 & 20.2 & $10 \pm 26$ \\
\hline
\end{tabular}

[22]. Huxley et al. found in their study that women with diabetes had higher risk of having a heart disease than men [23]. Sharrett et al. found in their study that high LDL and low HDL were associated with CVD [24]. It has been reported that the probability of having hypertension was threefold in the obese [25].

We found in our study that each of the women had at least two risk factors for heart diseases. This result suggests that awareness is low in women and they do not put the knowledge they have into practice in their lives. The percentage of 
women who have a risk level of $4(17 \%)$ is nothing to be overlooked. It can be said that these risk factors increase because people in this region eat more saturated fat and animal food and lead a sedentary life due to long and snowy winter months.

In heart diseases, an early intervention may be helpful in preventing the progression of the disease to a large extent. In a study, a program for protection from heart diseases that was administered to individuals was very beneficial in preventing the disease [26]. This shows the significance of risk assessment and trainings in heart diseases.

In conclusion, it was seen that women had the knowledge but did not practice it in their lives. Screening women for CVD risk and informing them accordingly as well as identifying those with higher CVD risk and monitoring them are important in terms of protection from CVD, early diagnosis, and treatment. Since individuals' awareness of being at risk will enhance participation in screening programs, nurses should determine risk levels of women through trainings they will organize and should share the results with them. Nurses can increase awareness by providing training to individuals.

Limitations and Generalizability of the Study. The fact that the study was conducted in a primary healthcare center in the province of Erzurum, Turkey, is the limitation of this study. Therefore, the results obtained in the study may be generalized only for this study group.

Recommendations. As multidisciplinary team members, nurses can develop programs to protect individuals from heart diseases by making use of this study. They can organize seminars enriched with written and visual materials to enlighten people. Risk factors specific to women in heart diseases (e.g., menopause, depression, and thyroid disorders) can be emphasized. Additionally, screening people for CVD risk, informing them accordingly, and monitoring them are important in terms of protection from CVD, early diagnosis, and treatment.

\section{Conflict of Interests}

The authors declare that there is no conflict of interests regarding the publication of this paper.

\section{References}

[1] M. Mitka, "Heart disease a global health threat," The Journal of the American Medical Association, vol. 291, no. 21, Article ID $2533,2004$.

[2] A. D. Callow, "Cardiovascular disease 2005-the global picture," Vascular Pharmacology, vol. 45, no. 5, pp. 302-307, 2006.

[3] H. Watkins and M. Farrall, "Genetic susceptibility to coronary artery disease: from promise to progress," Nature Reviews Genetics, vol. 7, no. 3, pp. 163-173, 2006.

[4] Turkish Republic Ministry of Health, Turkey Heart and Vascular Diseases Prevention and Control Program, Anıl Typography, Ankara, Turkey, 2008.

[5] U. N. Khot, M. B. Khot, C. T. Bajzer et al., "Prevalence of conventional risk factors in patients with coronary heart disease," The Journal of the American Medical Association, vol. 290, no. 7, pp. 898-904, 2003.

[6] J. Wagner, K. Lacey, D. Chyun, and G. Abbott, "Development of a questionnaire to measure heart disease risk knowledge in people with diabetes: the Heart Disease Fact Questionnaire," Patient Education and Counseling, vol. 58, no. 1, pp. 82-87, 2005.

[7] İ. Arikan, S. Metintaş, C. Kalyoncu, and Z. Yildiz, "Cardiovascular Disease Risk Factors Knowledge Level (CARRF-KL) Scale reliability and validity," Archives of the Turkish Society of Cardiology, vol. 37, no. 1, pp. 35-40, 2009.

[8] R. Jiles, E. Hughes, W. Murphy et al., "Surveillance for certain health behaviors among states and selected local areasBehavioral Risk Factor Surveillance System, United States, 2003," Morbidity and Mortality Weekly Report, vol. 54, no. 8, pp. 1-116, 2005.

[9] M. S. Biswas, P. S. Calhoun, H. B. Bosworth, and L. A. Bastian, "Are women worrying about heart disease?" Women's Health Issues, vol. 12, no. 4, pp. 204-211, 2002.

[10] R. Crouch and A. Wilson, "An exploration of rural women's knowledge of heart disease and the association with lifestyle behaviours," International Journal of Nursing Practice, vol. 17, no. 3, pp. 238-245, 2011.

[11] Hacettepe University Institute of Population, "Turkey demographic and health survey," Ministry of Health Maternal and Child Health and Family Planning General Directorate, Prime Ministry State Planning Organization ve TÜBİTAK, Ankara, Turkey, 2008.

[12] A. Onat, "Obesity, cardiovascular disease in turkey effect," Journal of Cardiology, vol. 31, no. 5, pp. 279-289, 2003.

[13] O. Kozan, A. Oğuz, A. Abacı et al., "Prevalence of the metabolic syndrome among Turkish adults," European Journal of Clinical Nutrition, vol. 61, no. 4, pp. 548-553, 2007.

[14] H. Hatemi, N. Turan, N. Arık, and V. Yumuk, "Obesity and hypertension screening results Turkey (TOHTA)," Trends in Endocrinology Journal, vol. 11, pp. 1-16, 2002.

[15] WHO, "Global strategy on diet, physical activity and health, Physical Activity," 2011, http://www.who.int/dietphysicalactivity/ pa/en/index.html.

[16] Ministry of Health and General Directorate of Primary Health Care, Let's Eat Healthy, Cardiac Health Project Research Report, Ministry of Health and General Directorate of Primary Health Care, 1st edition, 2004.

[17] Ministry of Health, National Household Survey Key Findings 2003, School of Public Health Directorate, Refik Saydam Hygiene Center, Ministry of Health, 1st edition, 2006.

[18] E. Işık, Y. Kanbay, Ö. Aslan, K. Işık, and S. Çınar, Presented to the Department of Family Medicine and Factors Affecting Individuals Prevalence of Obesity in: Artvin Example, Public Health Activities-HASUDER 15, National Public Health Congress.

[19] E. Gocgeldi, M. A. Babayiǧit, H. Hassoy, C. H. Acıkel, I. TaşcıI, and S. Ceylan, "With a diagnosis of hypertension patients' perceived quality of life and evaluation of the factors affecting," Gulhane Medical Journal, vol. 50, pp. 172-179, 2008.

[20] L. Rosenberg, J. R. Palmer, and S. Shapiro, "Decline in the risk of myocardial infarction among women who stop smoking," The New England Journal of Medicine, vol. 322, no. 4, pp. 213-217, 1990.

[21] I. Kawachi, G. A. Colditz, M. J. Stampfer et al., "Smoking cessation and time course of decreased risks of coronary heart disease in middle-aged women," Archives of Internal Medicine, vol. 154, no. 2, pp. 169-175, 1994. 
[22] N. Mahanonda, K. Bhuripanyo, W. Leowattana et al., "Regular exercise and cardiovascular risk factors," Journal of the Medical Association of Thailand, vol. 83, no. 2, pp. 153-158, 2000.

[23] R. Huxley, F. Barzi, and M. Woodward, "Excess risk of fatal coronary heart disease associated with diabetes in men and women: meta-analysis of 37 prospective cohort studies," British Medical Journal, vol. 332, no. 7533, pp. 73-78, 2006.

[24] A. R. Sharrett, C. M. Ballantyne, S. A. Coady et al., "Coronary heart disease prediction from lipoprotein cholesterol levels, triglycerides, lipoprotein(a), apolipoproteins A-I and B, and HDL density subfractions: the Atherosclerosis Risk in Communities (ARIC) Study," Circulation, vol. 104, no. 10, pp. 1108-1113, 2001.

[25] A. Kaya, "Obesity and hypertension," Turkish Journal of Endocrinology and Metabolism, vol. 2, pp. 13-21, 2003.

[26] J. Wong and S. Wong, "Trends in lifestyle cardiovascular risk factors in women: analysis from the Canadian National Population Health Survey," International Journal of Nursing Studies, vol. 39, no. 2, pp. 229-242, 2002. 


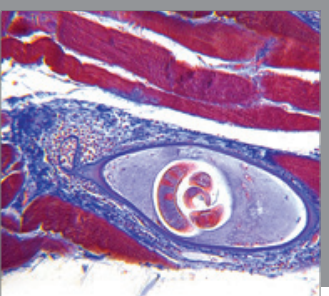

Gastroenterology

Research and Practice
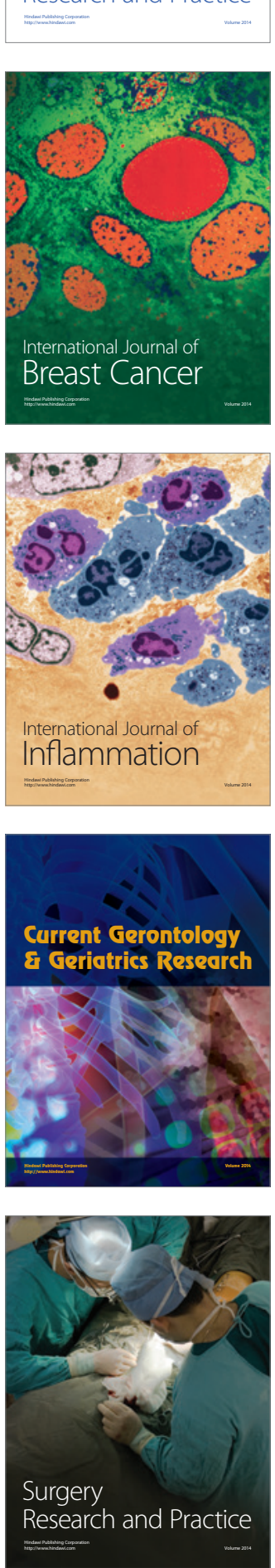

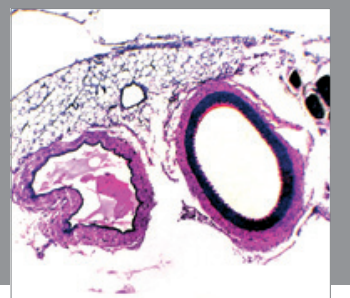

International Journal of Hypertension
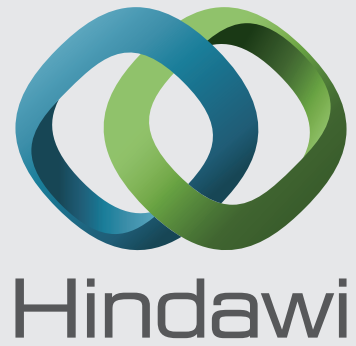

Submit your manuscripts at http://www.hindawi.com
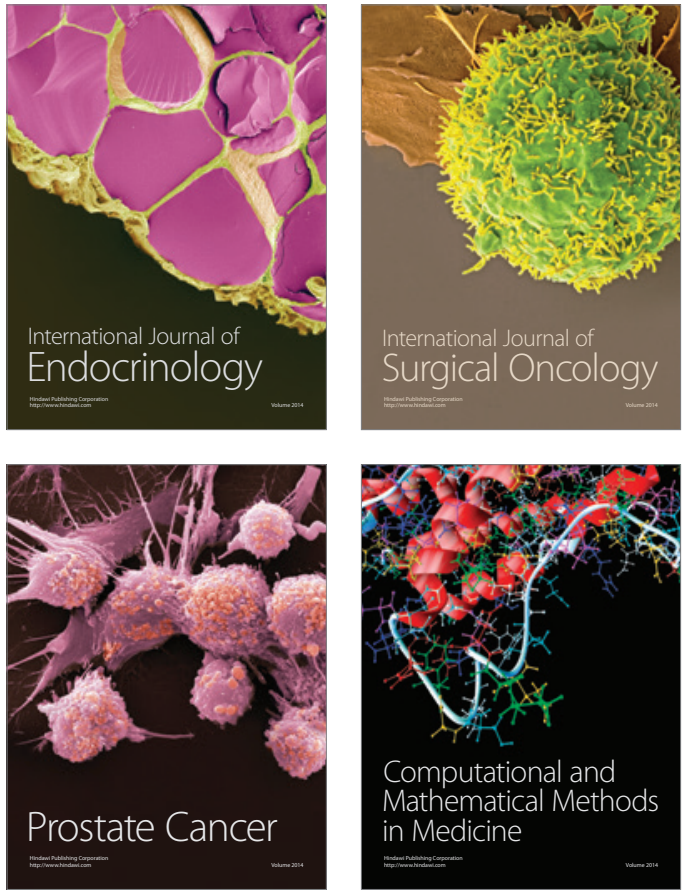
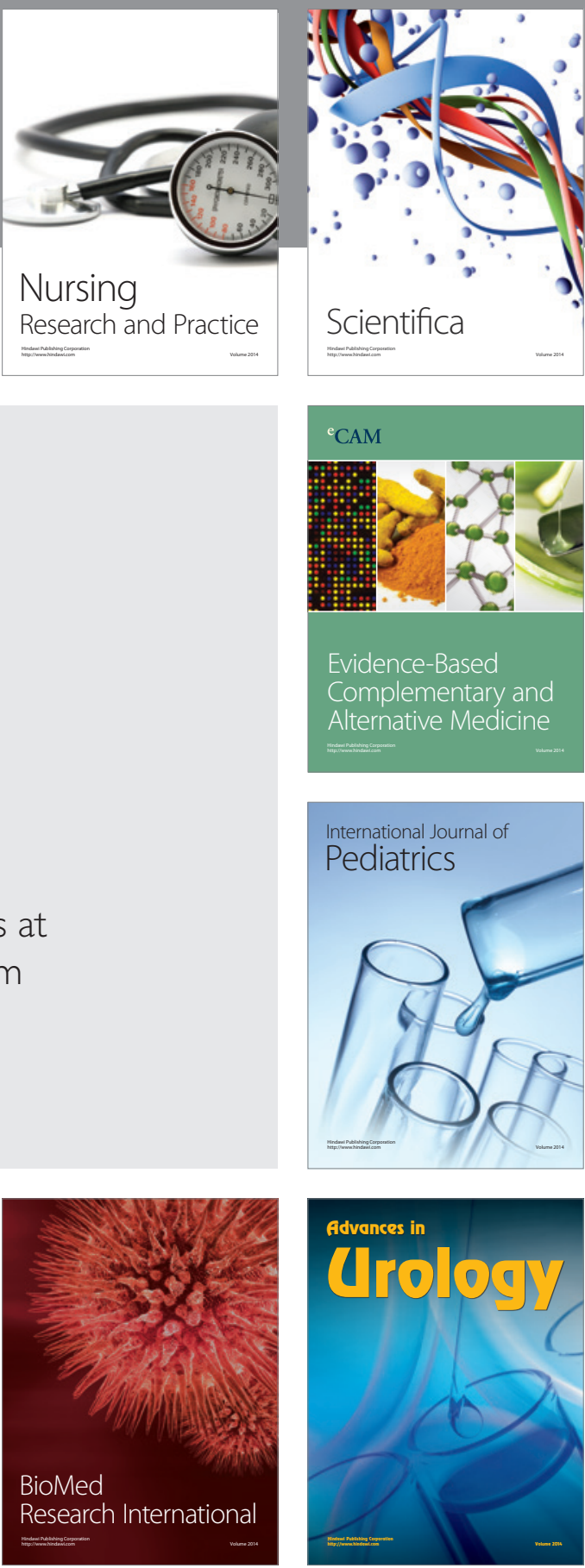

Nursing

Research and Practice

Scientifica

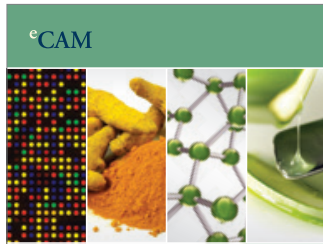

Evidence-Based

Complementary and Alternative Medicine
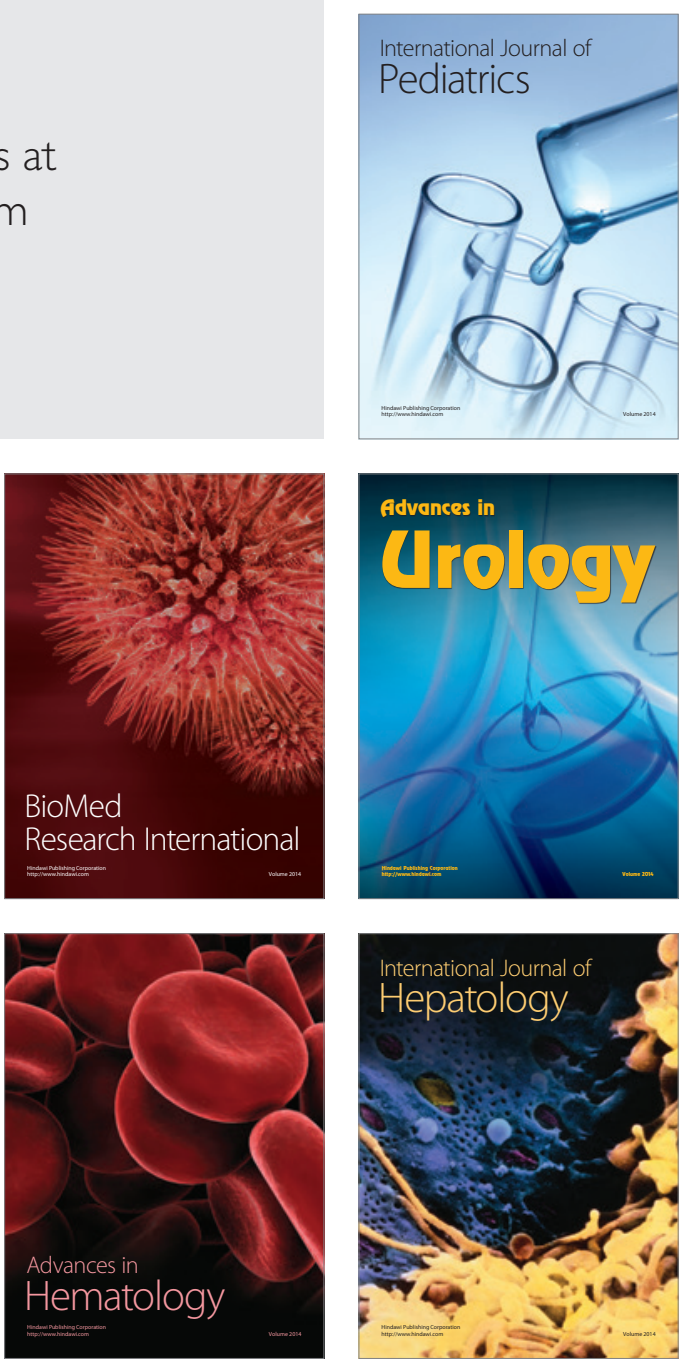